\title{
HIPÓTESES ABDUTIVAS ANTEFACTUAIS EM SITUAÇÕES PROATIVAS DE CRIAÇÃO DE CAMPANHAS PUBLICITÁRIAS: ANÁLISE COM BASE NA TEORIA DE CONCILIAÇÃO DE METAS
}

\author{
Fábio José RAUEN ${ }^{1}$ \\ Suelen Francez Machado LUCIANO ${ }^{2}$
}

\begin{abstract}
Resumo: Analisamos neste artigo o processo de formulação, execução e checagem de insights em situações proativas de criação de campanhas publicitárias a partir da modelação abdutivo-dedutiva fornecida pela teoria de conciliação de metas de Rauen (2014). Assumimos que a criatividade na publicidade é superordenada por metas que a equipe de atendimento da agência publicitária negocia com os clientes, materializa em briefings e entrega à equipe de criação. Neste contexto, argumentamos que a emergência e a avaliação de insights podem ser mais bem compreendidas concebendo-os como hipóteses abdutivas antefactuais em direção à heteroconciliação de metas previamente definidas nos briefings. Para ilustrar nosso argumento, analisamos um vídeo publicado pela agência AlmapBBDO, relatando o case da promoção do carro Fox da Volkswagen no Planeta Terra Festival.
\end{abstract}

Palavras-chave: Teoria de conciliação de metas. Modelação proativa de metas. Hipóteses abdutivas antefactuais. Publicidade. Criação publicitária.

\footnotetext{
${ }^{1}$ UNISUL - Universidade do Sul de Santa Catarina - Programa de Pós-graduação em Ciências da Linguagem. Tubarão - Santa Catarina - Brasil. 88704-900 - fabio.rauen@unisul.br

2 UNISUL - Universidade do Sul de Santa Catarina - Programa de Pós-graduação em Ciências da Linguagem. Tubarão - Santa Catarina - Brasil. 88704-900 - suelen.francez@gmail.com
} 


\section{Introdução}

Sem deixar de reconhecer que há diferentes abordagens teórico-críticas sobre a natureza e a função da publicidade, nossa atenção neste artigo está centrada na emergência criativa de insights materializados nestes contextos, assumindo que ela é (a) superordenada por metas negociadas pela equipe de atendimento da agência e (b) caracterizada por processos comunicacionais ostensivo-inferenciais complexos, passíveis de serem descritos e explicados de um ponto de vista pragmático-cognitivo.

Nesse sentido, argumentamos que o percurso criativo no mercado publicitário é constrangido pelo anunciante quando suas intenções são negociadas com a equipe de atendimento da agência e materializadas num briefing. Conforme Corrêa (2002), um briefing é um documento que, reunindo um conjunto de dados fornecidos pelo anunciante, orienta a elaboração de campanhas publicitárias pelos profissionais de criação. Quanto mais completo um briefing é, mais elementos a agência possui para criar uma solução que atenda às expectativas do anunciante. Segundo Hansen (2013, p. 74), um briefing não somente "elenca as variáveis do problema a ser resolvido", mas "direciona, norteia e seleciona o caminho (o sentido) a ser seguido no processo criativo do discurso publicitário”. Desse modo, cabe aos profissionais de criação interpretá-lo e definir a melhor maneira de transmitir seus propósitos, produzindo algo que torne desejado o que é anunciado ao mesmo tempo em que atinge com eficiência as metas descritas no documento.

Ao conectar a noção de criatividade com a noção de meta, estamos interessados, neste artigo, no raciocínio criativo que é utilizado em um contexto determinado e para um fim específico. Vale destacar que não estamos tomando partido sobre a intencionalidade da produção publicitária; mas, especificamente, observando seu efetivo funcionamento mediante certo olhar teórico. Como Weisberg (2007), tomamos como indivíduo criativo aquele que produz intencionalmente uma novidade na tentativa de atingir um objetivo. Uma teoria que lida com esses processos nessa mesma linha de argumentação é a teoria de conciliação de metas de Rauen (2014), para quem a cognição é movida proativamente por metas, cuja consecução é mediada por hipóteses abdutivas antefactuais que conectam premissas convenientes a conclusões fixas ${ }^{3}$. Esse parece ser o caso do profissional de

\footnotetext{
${ }^{3}$ Ver Luciano (2014), Cardoso (2015), Vieira (2015), Bez (2016) e Caldeira (2016).
} 
criação cujo desafio consiste em abduzir uma hipótese ótima para a consecução da meta do anunciante.

Diante dessa breve contextualização, ilustramos neste artigo como pode ser descrito e explicado o suposto processo de elaboração, de execução e de checagem de hipóteses abdutivas antefactuais em situações proativas de criação de campanhas publicitárias, valendo-nos do aparato descritivo e explanatório da teoria de conciliação de metas. Para tanto, analisamos um vídeo publicado pela agência AlmapBBDO, relatando o case da promoção do carro Fox da Volkswagen no Planeta Terra Festival.

Para dar conta dessa demanda, o texto foi organizado em mais cinco seções dedicadas, respectivamente, à publicidade e ao processo criativo, à modelação proativa de metas, à arquitetura descritivo-explanatória da teoria de conciliação de metas, à noção de gradação de força de hipóteses abdutivas e às considerações finais.

\section{O processo criativo na publicidade}

No contexto mais restrito da literatura da publicidade, Dualibi e Simonsen (2000, p. XVI, grifo do autor) argumentam que, embora a palavra "criatividade" tenha sido razoavelmente confundida com "a técnica de criar anúncios", ela é antes uma "técnica de resolver problemas". O processo criativo, segundo eles, não parte apenas da necessidade de se criar um anúncio para um determinado produto, mas também da demanda de se criar um anúncio para a resolução de um problema.

Bertomeu (2002, p. 18) afirma que a definição de criatividade e de produto criativo em publicidade precisa não apenas estar associada a "aspectos originais e ousados", mas também ser "apropriada a uma dada situação". Assim, "a comunicação publicitária deve ser um instrumento afiadíssimo de interpretação das necessidades do cliente para auxiliá-lo de forma certeira a atingir seus objetivos mercadológicos" (BERTOMEU, 2002, p. 18).

Hansen (2013) argumenta haver um tripé composto pelo anunciante, pela agência de publicidade e pelo público-alvo que ordena o discurso publicitário. Nesse tripé, “a base da pirâmide é formada pelo anunciante e pelo público-alvo, responsáveis pela sustentação da publicidade e pelo fornecimento de subsídios (produtos, serviços, marcas, poder de consumo) para que a agência possa exercer sua atividade e constituir o seu campo de 
atuação" (HANSEN, 2013, p. 33). Por sua vez, a agência de publicidade está no topo da pirâmide, porque cabe a ela conectar o público-alvo ao produto anunciado mediante estímulos criativos chamativos, divertidos e informativos. Conforme Carrascoza (2008, p. 18), os profissionais de criação "atuam cortando, associando, unindo e, consequentemente, editando informações do repertório cultural da sociedade" para estabelecer essa conexão.

O processo criativo em grandes agências decorre de uma cadeia comunicativa que se inicia no contato do setor de atendimento com o anunciante. Entre as atribuições do setor de atendimento "mais próximas ao processo criativo" está a "elaboração do briefing e a apresentação da campanha publicitária para a aprovação final junto ao cliente" (HANSEN, 2013, p. 31). Por sua vez, a criação de conceitos, ideias e imagens que constituem as campanhas publicitárias em si é desenvolvida por redatores e diretores de arte. Orientado pelo diretor de criação, cabe aos redatores criar os elementos verbais que compõem o anúncio e cabe aos diretores de arte criar os elementos não verbais, fazendo o rafe (primeiro esboço) e o layout das peças publicitárias.

No contexto desta cadeia de relações - onde o discurso do profissional de criação é uma interpretação do discurso do atendimento, e o discurso do atendimento é uma interpretação do discurso do anunciante - destacamos neste estudo o briefing, uma vez que esse documento sintetiza as relações comunicativas entre os três atores envolvidos: anunciante (cliente), atendimento e criação. Para Bertomeu (2002, p. 31), o briefing é "um documento centralizador e abrangente em termos de informações gerais, e pode ser considerado um aglutinador de informações entre todos os profissionais e áreas envolvidas". Cabe a este documento, além disso, definir a principal mensagem que o anúncio aspira a propagar.

Reunindo informações indispensáveis à ocorrência do processo criativo, o briefing mostra-se útil ao estabelecer limites à criação em direção a um objetivo determinado. Nesse sentido, Vieira (2001) argumenta que é preciso definir claramente no briefing o que se pretende com a campanha publicitária antes de se dispor a criá-la.

Para Nachmanovitch (1993, p. 84), esses constrangimentos estabelecidos ao processo criativo são importantes, pois "trabalhar dentro dos limites impostos pelo meio nos obriga a mudar nossos próprios limites". Hansen (2013, p. 55) pondera que "ser criativo no universo da publicidade é saber lidar com as circunstâncias dadas para a 
formulação do discurso publicitário; é conseguir se adaptar às adversidades, adequandose às impossibilidades e oferecendo uma ideia criativa na relação custo-benefício". Conforme Phillips (2008), um briefing bem elaborado pode estimular a criatividade e contribuir com a abreviação do tempo de conclusão de um trabalho. O briefing não bloqueia o processo criativo, mas o direciona.

Assumindo que a criação publicitária ocorre num contexto constrangido por metas descritas no briefing, a próxima seção pretende ilustrar como isso ocorre a partir do aparato descritivo e explanatório da teoria de conciliação de metas.

\section{Modelação proativa de metas}

Em essência, a teoria de conciliação de metas de Rauen (2014) conecta, do ponto de vista simbólico, a noção de relevância com a noção de meta. $\mathrm{O}$ autor concebe relevância tal como proposta pela teoria da relevância de Sperber e Wilson $(1986,1995)$, ou seja, uma propriedade dos inputs direcionados aos processos cognitivos. Segundo a teoria da relevância, um estímulo ostensivo, quando processado no contexto de suposições cognitivas prévias de um indivíduo, pode gerar certos efeitos cognitivos positivos de fortalecimento dessas suposições, de contradição/eliminação dessas suposições, ou mesmo de combinações com essas suposições para a geração de implicações cognitivas. Um estímulo diz-se relevante quando essas alterações superam o esforço cognitivo necessário para produzi-las.

Sperber e Wilson $(1986,1995)$ assumem que a cognição humana maximiza os efeitos cognitivos dos estímulos que processa - princípio cognitivo de relevância - $\mathrm{e}$ processa estímulos comunicacionais presumindo sua relevância ótima - princípio comunicativo de relevância. Eles argumentam que um enunciado é otimamente relevante quando é suficientemente relevante para merecer ser processado e, simultaneamente, é o estímulo mais relevante que o emissor se dispôs a ou foi capaz de produzir. Cabe ao intérprete, por sua vez, elaborar uma interpretação que satisfaça essa expectativa de relevância ótima. O intérprete faz isso por meio de uma heurística de compreensão guiada pela noção de relevância, segundo a qual, baseando-se na codificação linguística, ele segue uma rota de esforço mínimo na computação de efeitos cognitivos, considera 
interpretações em ordem de acessibilidade e para quando sua expectativa de relevância é satisfeita.

Lindsay e Gorayska (2004), contudo, argumentam que a própria noção de relevância é dependente de uma noção de meta. Para eles, metas G são representações simbólicas de necessidades e desejos, embora geralmente representem estados reais. Assim, um estímulo $\mathrm{P}$ qualquer não é relevante em si mesmo, mas relevante em conexão com uma meta G. Textualmente, "P é relevante para G, se e somente se, G é uma meta e P é um elemento essencial de algum plano que é suficiente para alcançar G" (LINDSAY; GORAYSKA, 2004, p. 2).

Conforme Lindsay e Gorayska (2004, p. 8-9), as metas podem ser cognitivas ou finais. As metas cognitivas contribuem para a construção ou execução de um plano de nível mais alto, cooperando com o alcance de metas finais. As metas finais são hipóteses sobre um estado possível do mundo e estão associadas com o sistema motivacional dos indivíduos.

Segundo Rauen (2014, p. 595, tradução nossa):
A maioria das metas é parte de uma cadeia complexa de metas. Uma meta cognitiva decorre de, justifica-se por ou contribui para a elaboração ou a execução de metas finais, de maneira que sua especificação associa-se a condições de satisfação que o agente acredita estarem alcançadas quando ele se encontra no estado de meta final.

Neste estudo, presumimos que a elaboração da campanha publicitária é superordenada por uma meta final definida explicitamente no briefing. Para atingi-la, os profissionais de criação movem-se por um conjunto complexo de metas cognitivas intermediárias que podem ser subsumidas pela ideia de "elaboração da campanha publicitária”. Posto isso, nenhuma ação é relevante por si mesma, mas relevante no escopo dessas cadeias de metas e submetas ${ }^{4}$.

Com relação aos processos cognitivos envolvidos na interpretação de inputs verbais, Sperber e Wilson (2001) defendem que esse processo se dá através de um mecanismo ou módulo dedutivo que tem a função de fazer a derivação de modo não trivial e não demonstrativo de todas as conclusões possíveis. Rauen (2014), por sua vez, endossa

\footnotetext{
${ }^{4}$ Vale mencionar que é somente dentro do escopo de uma cadeia de metas e submetas que se justifica o aumento de esforços de processamento no contexto de efeitos cognitivos positivos duvidosos - um fenômeno de difícil tratamento no interior da teoria de relevância standard.
} 
esse mecanismo, mas defende que essa modelação é restritiva e reativa, uma vez que o mecanismo é mobilizado apenas em decorrência da emergência do estímulo.

Sendo assim, ancorado na teoria da relevância de Sperber e Wilson (2001), Rauen (2014) propõe um mecanismo que modela a ampliação de contexto cognitivo, bem como a proatividade humana. A tese central do autor é a de que a ampliação do contexto cognitivo é abdutiva e de que a cognição é movida antes por uma conclusão antecipada do que por premissas. Logo, o processamento dedutivo apenas compõe o processo responsável pela avaliação e pela checagem das hipóteses abdutivas.

Ao contínuo, o autor desenvolve uma arquitetura descritiva e explanatória que abarca desde a projeção da meta até a checagem da hipótese abdutiva antefactual escolhida pelo indivíduo como sendo a primeira hipótese condizente com o princípio de relevância, cujo efeito cognitivo supera o custo de processamento. Rauen (2014), então, conecta as noções de relevância e de meta ao propor um enfoque abdutivo-dedutivo para a modelação proativa de metas. Ele defende que metas guiam as ações humanas e que a relevância guia a escolha da hipótese supostamente mais eficiente/relevante para a consecução dessas metas, desde que respeitadas as habilidades e preferências do indivíduo. Conforme o autor (2014, p. 596, tradução nossa), “o indivíduo produz uma inferência à melhor solução, numa franca analogia ao conceito de inferência à melhor explicação de Harman (1965), de modo que ele ajusta a premissa que melhor concorre para a consecução da meta"”.

\section{Arquitetura descritivo-explanatória da teoria de conciliação de metas}

Para ilustrar como a abordagem teórica guiada pela noção de conciliação de metas pode descrever e explicar a emergência e a avaliação de insights para a elaboração de uma

\footnotetext{
${ }^{5}$ Não queremos definir por inferência à melhor solução uma noção forte de "a melhor solução", mas uma noção ad hoc de solução ótima, ou seja, a melhor solução disponível em contextos cognitivos restringidos por variáveis externas ou internas ao indivíduo (preferências e habilidades do indivíduo, por exemplo).
} 
peça publicitária ${ }^{6}$, analisamos em seguida o $\operatorname{case}^{7}$ da promoção do carro Fox da Volkswagen $^{8}$ no Planeta Terra Festival produzido pela agência AlmapBBDO9

O modelo abdutivo-dedutivo de descrição e explicação de processos criativos para consecuções de metas de Rauen (2014) consiste de quatro estágios, a saber: projeção de uma meta, e formulação, execução e checagem de pelo menos uma hipótese abdutiva antefactual para a consecução dessa meta. Vejamos cada um desses estágios nas subseções a seguir.

\subsection{Projeção da meta}

O primeiro estágio da modelação consiste na projeção de uma meta. Rauen (2014, p. 599, tradução nossa) assim formaliza esse estágio:

[1] O indivíduo $i$ projeta uma meta $Q$ em $t_{l}$,

tal que:

a) $t_{1}$ representa o tempo da projeção da meta $Q$; e

b) a meta $Q$ é um estado futuro ainda não existente em $t_{l}$.

No case em análise, assumimos que, antes mesmo de o processo criativo ser mobilizado, anunciante e setor de atendimento da agência precisam negociar a meta da peça publicitária ${ }^{10}$ que superordenará o processo criativo e será materializada no briefing. A meta em questão foi a de gerar buzz de promoção do carro Fox da Volkswagen antes do Planeta Terra Festival com 30 ingressos. O Planeta Terra Festival é um festival de

\footnotetext{
${ }^{6}$ Por peça publicitária, definem-se produtos individuais que são criados para compor uma campanha publicitária.

7 Para conhecer o case, acesse: $<$ http://www.551121615600.com/awards/2011/planeta terra face/port/index.html $>$.

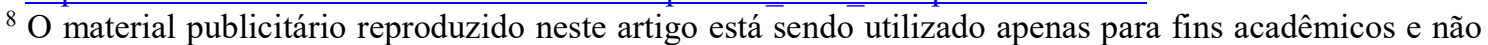
representa qualquer tipo de recomendação de produtos ou empresas por parte dos autores ou do periódico.

${ }^{9}$ A Almap (Alcântara Machado Publicidade) foi fundada em 1956 por Alex Periscinoto e Caio de Alcântara Machado. Em 1988, a Almap associou-se à BBDO do Grupo Omnicom. A empresa está entre as maiores agências de publicidade do Brasil. Disponível em: $<$ http://pt.wikipedia.org/wiki/AlmapBBDO $>$. Acesso em: 16 out. 2015.

${ }^{10}$ Ao desenvolver o conceito de conciliação de metas, Rauen (2014) distingue as noções de autoconciliação de heteroconciliação. $\mathrm{Na}$ autoconciliação, o indivíduo checa, ele mesmo, se as consecuções se conciliam com suas metas. Na heteroconciliação, essas checagens são desenvolvidas por pelo menos dois agentes através de estímulos ostensivo-inferenciais, em geral linguísticos, de modo que é necessária a coordenação colaborativa de metas entre eles. Neste estudo, admitimos que a negociação entre anunciante e setor de atendimento da agência para o estabelecimento da meta inserta no briefing é um exemplo típico de heteroconciliação linguística.
} 
música realizado na cidade de São Paulo desde 2007 que reúne milhares de jovens. Agência e cliente viram no festival uma oportunidade de gerar o que em marketing se chama de $b u z z^{11}$, ou seja, certa espécie de ação que procura disseminar produtos ou serviços através de cadeias comunicativas formadas pelos próprios consumidores. Nesta estratégia de marketing boca a boca, a meta é a de estimular as pessoas a repassar uma mensagem às outras. Esse tipo de ação é potencializado pela internet, de modo que uma mensagem pode atingir milhares ou até milhões de pessoas. Embora o buzz possa ocorrer ao acaso, ele pode ser iniciado deliberadamente, como é o caso da campanha da AlmapBBDO para a promoção do Fox da Volkswagen.

No caso em destaque, a meta poderia ser assim formulada:

[1] O publicitário ${ }^{12} i$ projeta a meta $Q$ de gerar buzz de promoção do carro Fox da Volkswagen antes do Planeta Terra Festival com 30 ingressos em $t_{l}$.

Nessa formulação, destaca-se que (a) o processo se inicia em $t_{1}$, que representa o tempo da emergência da necessidade de atingir a meta $Q$ de gerar buzz de promoção do carro Fox da Volkswagen antes do Planeta Terra Festival com 30 ingressos; e (b) a meta $Q$ é uma possibilidade futura ainda não existente no tempo $t_{1}$, o tempo da formulação da meta $Q$. Trata-se, assim, de uma representação mental de um estado desejado.

O output desse estágio pode ser representado proposicionalmente assim:

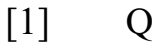

gerar buzz de promoção do carro Fox da Volkswagen antes do Planeta Terra Festival com 30 ingressos, publicitário.

Nos termos do case apresentado pela AlmapBBDO, "mesmo sendo um dos patrocinadores master do Planeta Terra Festival, a Volkswagen queria gerar um grande buzz antes do evento. Nossa tarefa [da agência] era fazer isso com um orçamento quase inexistente: 30 ingressos” (ALMAPBBDO, 2015). A locução do vídeo, que acompanha

\footnotetext{
${ }^{11}$ Literalmente, a expressão 'buzz' significa 'zumbido', 'zunido', 'murmúrio', 'rumor' ou 'bochicho'.

${ }^{12}$ Para efeitos de simplificação, por publicitário representamos todos os profissionais responsáveis pela criação desta peça publicitária, independente do papel que ocupam na cadeia produtiva.
} 
a apresentação do case, expressa a meta e o orçamento acordados com a Volkswagen para anunciar o carro Fox da seguinte forma:

O Planeta Terra é um dos maiores festivais de música do Brasil e atrai milhares de jovens do país inteiro. Em 2010, a Volkswagen foi um dos principais patrocinadores do evento, mas queria fazer um buzz para promover seu carro que mais fala com os jovens: o Fox. Nosso orçamento: 30 ingressos. (ALMAPBBDO, 2015, 1-22 seg., transcrição nossa).

A Figura 1, a seguir, captura o $14^{\circ}$ segundo do vídeo da AlmapBBDO que ilustra o case. Nessa tomada, destacando o carro Fox, podem ser vistos camarotes do Planeta Terra Festival patrocinados pela Volkswagen.

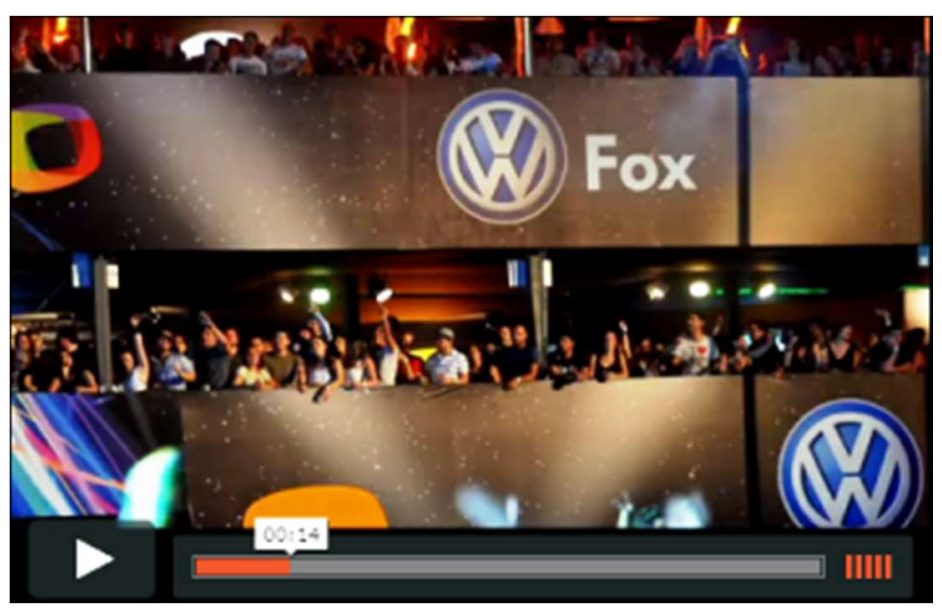

Figura 1: Projeção da Meta

Fonte: Imagem capturada do Vídeo da AlmapBBDO (2015, 14 seg.).

\subsection{Formulação de hipótese abdutiva antefactual}

Definida a meta, segue-se a formulação de pelo menos uma hipótese abdutiva antefactual que o publicitário $i$ considera ser plausível para alcançar a meta $Q$. Para tanto, o publicitário $i$ acessa suposições factuais de sua memória enciclopédica e escolhe pelo menos uma ação antecedente $P$ admitida como suficiente para atingir o estado consequente $Q$. A escolha de $P$ segue o princípio de relevância segundo o qual essa ação antecedente deve ensejar o menor custo de processamento possível diante do efeito fixo de se obter a meta $Q$. 
Rauen (2014, p. 599-600, tradução nossa) assim formaliza o segundo estágio:

[2] O indivíduo $i$ abduz uma hipótese antefactual $H_{a}$ para atingir a meta $Q$ em $t_{2}$,

tal que:

a) $t_{2}$ representa o tempo da formulação da hipótese abdutiva antefactual $H_{a}$;

b) $t_{2}$ sucede $t_{1}$

c) a hipótese abdutiva antefactual $H_{a}$ corresponde a uma formulação do tipo “Se $P$, então $Q$ ”, de modo que $P$ é uma ação antecedente e $Q$ é um estado consequente;

d) no escopo da hipótese abdutiva antefactual $H_{a}$, a meta $Q$ é admitida pelo indivíduo $i$ como um estado consequente;

e) no escopo da hipótese abdutiva antefactual $H_{a}$, uma ação antecedente $P$ é admitida pelo indivíduo $i$ como minimamente suficiente para atingir o estado consequente $Q$

f) a hipótese abdutiva antefactual $H_{a}$ é a primeira formulação consistente com o princípio de relevância, pois é aquela de menor custo de processamento diante do efeito fixo futuro projetado pelo estado consequente $Q$;

g) simultaneamente, a hipótese $H_{a}$ é tomada pelo indivíduo $i$ como a inferência à melhor solução plausível para atingir o estado consequente $Q$.

Como base nessa modelação, obtemos a formulação [2a], a seguir:

[2a] O publicitário $i$ abduz uma hipótese antefactual $H_{a}$ para atingir a meta $Q$ de gerar buzz de promoção do carro Fox da Volkswagen antes do Planeta Terra Festival com 30 ingressos em $t_{2}$.

Como podemos ver, a formulação [2a] ainda não traduz qual é a ação necessária para atingir a meta $Q$. Segundo Rauen (2014), para determinar qual é a hipótese abdutiva melhor ou mais relevante, alguns critérios precisam ser respeitados, a saber: a hipótese $H_{a}$ poder ser mapeada por uma formulação hipotética "Se $P$, então $Q$ ", tal que a ação antecedente $P$ implica o alcance ou a consecução da meta $Q$; a ação antecedente $P$ ser suficiente para a obtenção do estado consequente $Q$; a hipótese $H_{a}$ ser considerada a melhor solução para atingir $Q$; a hipótese $H_{a}$ ser a primeira suposição compatível com o princípio de relevância. 
É justamente nesta etapa que podem emergir hipóteses criativas de consecução da meta de gerar buzz de promoção do carro Fox antes do festival, e este é o ponto de interesse deste estudo. Supostamente, a memória enciclopédica do publicitário deve conter um número expressivo de suposições factuais que representam soluções possíveis para atingir a meta $Q$. Seguramente, muitas dessas soluções seriam propostas e descartadas em seguida em função das condições de produção da peça publicitária ${ }^{13}$.

Para fins de ilustração, imaginemos que o conjunto criativo de soluções do publicitário fosse arbitrariamente restringido ${ }^{14}$ apenas às suposições $S_{l-4}$ a seguir ${ }^{15}$ :

$S_{1}$ - Criar uma peça publicitária que concede 30 ingressos do Planeta Terra Festival através da ferramenta comentário do Facebook.

$S_{2}$ - Criar uma peça publicitária que concede 30 ingressos do Planeta Terra Festival através de e-mail marketing.

$S_{3}$ - Criar uma peça publicitária que concede 30 ingressos do Planeta Terra Festival através de outdoors.

$S_{4}$ - Criar uma peça publicitária que concede 30 ingressos do Planeta Terra Festival através de sinais de fumaça.

O que queremos modelar com essas alternativas restringidas arbitrariamente é que a hipótese abdutiva antefactual $H_{a}$ a ser escolhida deve atender aos quatro critérios propostos por Rauen (2014). As soluções $S_{1-4}$ podem ser mapeadas por uma formulação hipotética "Se P, então Q", de tal modo que a ação antecedente $P$ implica o alcance ou consecução da meta $Q$. Elas também podem ser consideradas suficientes para a promoção do estado consequente Q, uma vez que o buzz pode ser gerado por sinais de fumaça, outdoors, e-mails marketing e comentários do Facebook. Todavia, as soluções $S_{1-4}$ são significativamente diferentes quando confrontadas com os critérios de exequibilidade e relevância. $S_{4}$ é inexequível, pois é difícil perceber como operacionalizar sinais de fumaça neste contexto. $S_{3}$ é exequível, mas de alto custo, quando o orçamento é restrito a 30 ingressos. $S_{2}$ usa ferramentas virtuais, é plausível, mas requer a obtenção de lista de $e$ -

\footnotetext{
${ }^{13}$ É necessário ressalvar que, dada a rapidez como hipóteses abdutivas antefactuais emergentes são rejeitadas em seguida, uma hipótese abdutiva antefactual pode ser descartada sem passar, necessariamente, por todos os quatro estágios propostos por Rauen (2014). Ou seja, um indivíduo pode descartar hipóteses sem testá-las.

${ }^{14}$ Neste artigo, o contexto é arbitrariamente restringido porque não tivemos acesso ao contexto real de emergência das ideias desta campanha. Fosse esse o caso, ainda assim caberia questionar o descarte de ideias emergentes antes mesmo de se tornarem públicas.

${ }^{15}$ Uma vez que o que se está modelando é o processo de emergência e de escolha de uma hipótese abdutiva antefactual que conecta uma ação antecedente viável em direção à consecução de uma meta, assumiremos que todas as suposições $S_{l-4}$ são plausíveis independentemente de sua exequibilidade concreta.
} 
mails do público-alvo que se deseja atingir, quando o orçamento da campanha era, nos termos da própria agência, "quase inexistente: 30 ingressos". $S_{l}$, nesse cenário arbitrariamente restringido de suposições $S_{1-4}$, é a solução mais relevante e factível. O Facebook tem a vantagem evidente de atingir um número expressivo de pessoas e, melhor ainda, atingi-las com baixo custo.

Assim sendo, a suposição $S_{l}$ pode ser admitida como a hipótese que melhor atende aos quatro critérios. Ela se deixa mapear numa formulação hipotética, uma vez que "se o publicitário criar uma peça publicitária que concede 30 ingressos do Planeta Terra Festival através da ferramenta “comentário" do Facebook, então o publicitário gerará buzz de promoção do carro Fox da Volkswagen antes do Planeta Terra Festival com 30 ingressos". Ela é uma ação pelo menos suficiente para gerar o buzz de promoção. Ela é uma hipótese de baixo custo de processamento diante do efeito fixo de gerar esse buzz. E, finalmente, ela é uma hipótese que atende ao critério de melhor solução, uma vez que tem o duplo efeito de atingir a meta $Q$ e ser gratuita. Logo, podemos supor que a hipótese abdutiva antefactual $H_{a}$ mais relevante e plausível neste contexto ad hoc é a que segue.

[2b] Se o publicitário $i$ criar uma peça publicitária que concede 30 ingressos do Planeta Terra Festival através da ferramenta comentário do Facebook, então o publicitário $i$ gerará buzz de promoção do carro Fox da Volkswagen antes do Planeta Terra Festival com 30 ingressos.

O output de [2b] pode ser representado de maneira esquemática como segue:

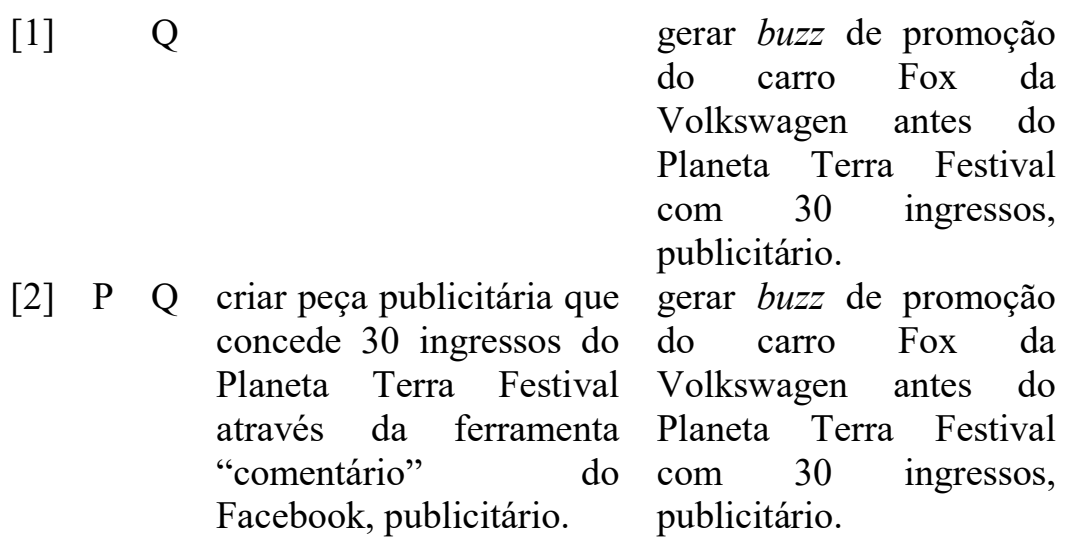


No case em análise, a AlmapBBDO (2015) assim expressa a solução encontrada para atingir a meta proposta pelo anunciante: "Nossa ideia: explorar a ferramenta mais básica do Facebook: o comentário". A solução é expressa de modo ligeiramente diferente na locução do vídeo que ilustra o case: "Decidimos explorar a ferramenta mais básica e popular do Facebook: o comentário ${ }^{16 "}$. A Figura 2, a seguir, captura o $28^{\circ}$ segundo do vídeo e ilustra como a agência destaca visualmente a solução encontrada.

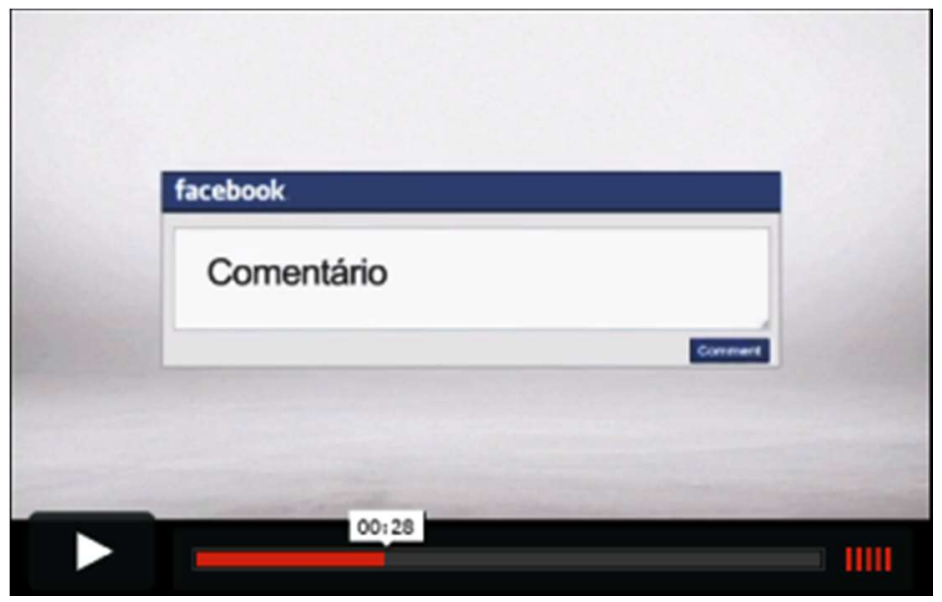

Figura 2: Formulação da hipótese abdutiva antefactual

Fonte: Imagem capturada do Vídeo da AlmapPBDO (2015, 28 seg.).

\subsection{Execução da hipótese abdutiva antefactual}

Uma vez escolhida a hipótese abdutiva antefactual, ocorre a provável execução da ação antecedente $P$ no terceiro estágio.

Vejamos as respectivas formulações.

[3a] O indivíduo $i$ executa $P$ para atingir $Q$ em $t_{3}$, ou [3b] O indivíduo $i$ não executa $P$ para atingir $Q$ em $t_{3}$,

tal que:

a) $t_{3}$ representa o tempo da execução da ação antecedente $P$ no contexto da formulação hipotética "Se $P$, então $Q$ ";

b) $t_{3}$ sucede $t_{2}$;

c) [3b] é o modelo de inação pressuposto por [3a];

\footnotetext{
${ }^{16}$ No texto do site e no áudio do vídeo, segue-se imediatamente a operacionalização da ideia. Embora a operacionalização da ideia consista de submetas em direção à consecução da ação antecedente e, desse modo, devesse compor a ideia em si, julgamos mais conveniente apresentá-las mais à frente no estágio de execução.
} 
d) A inação pode ser voluntária ou involuntária. (RAUEN, 2014, p. 601602 , tradução nossa).

O output ativo do terceiro estágio pode ser visto a seguir:

[3] O publicitário $i$ executa a criação de uma peça que concede 30 ingressos do Planeta Terra Festival através da ferramenta "comentário" do Facebook $P$ para gerar buzz de promoção do carro Fox da Volkswagen antes do Planeta Terra Festival com 30 ingressos $Q$ num tempo $t_{3}$.

Ou, de modo mais esquemático:

\begin{tabular}{|c|c|c|c|c|}
\hline [1] & & Q & & $\begin{array}{lll}\text { gerar buzz de promoção } \\
\text { do carro } & \text { Fox da } \\
\text { Volkswagen } & \text { antes do }\end{array}$ \\
\hline & & & & $\begin{array}{l}\text { Planeta Terra Festival } \\
\text { com } 30 \text { ingressos, } \\
\text { publicitário. }\end{array}$ \\
\hline 21 & $\mathrm{P}$ & Q & $\begin{array}{l}\text { criar peça publicitária que } \\
\text { concede } 30 \text { ingressos do }\end{array}$ & 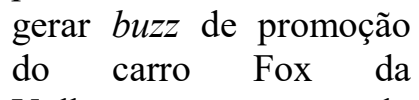 \\
\hline & & & $\begin{array}{lrr}\text { Planeta Terra Festival } \\
\text { através da } & \text { ferramenta } \\
\text { "comentário" } & \text { do }\end{array}$ & $\begin{array}{l}\text { Volkswagen antes do } \\
\text { Planeta Terra Festival } \\
\text { com } 30 \text { ingressos, }\end{array}$ \\
\hline [3] & $\mathrm{P}$ & & $\begin{array}{l}\text { Facebook, publicitário. } \\
\text { criar peça publicitária que } \\
\text { concede } 30 \text { ingressos do }\end{array}$ & publicitário. \\
\hline & & & $\begin{array}{lrr}\text { Planeta } & \text { Terra } & \text { Festival } \\
\text { através da } & \text { ferramenta } \\
\text { "comentário" } & \text { do }\end{array}$ & \\
\hline & & & Facebook, publicitário. & \\
\hline
\end{tabular}

Segundo a agência AlmapBBDO, a peça publicitária foi executada como se segue.

[...] Dias antes do evento, nós escaneamos cada um dos nossos ingressos e escondemos 3 dígitos de cada número de série, depois subimos os ingressos na nossa página do Facebook. Simples assim: o primeiro usuário a adivinhar os 3 números escondidos, levava o ingresso. Ingresso após ingresso, por trinta vezes. (ALMAPBBDO, 2015).

Por sua vez, a locução do vídeo que ilustra o case assim se expressa: 
[...] Quando faltavam poucos dias para o Planeta Terra e os ingressos já chegavam a preços astronômicos, nós calmamente escaneamos cada um dos nossos 30 ingressos. Depois, escondemos três dígitos do código de barra de cada um deles. Aí, foi só subir um por um no Facebook e deixar rolar. Simples assim: o primeiro a acertar, levava o ingresso. Ingresso por ingresso, trinta vezes. [...]. (ALMAPBBDO, 2015, 29-66 seg., transcrição nossa).

As Figuras 3 e 4, a seguir, capturam o $48^{\circ}$ segundo do vídeo, ilustrando como a agência havia escondido os três últimos números dos 30 ingressos a serem sorteados, e o $62^{\circ}$ segundo, ilustrando como o site comunicava o sorteio do ingresso ao usuário do Facebook.

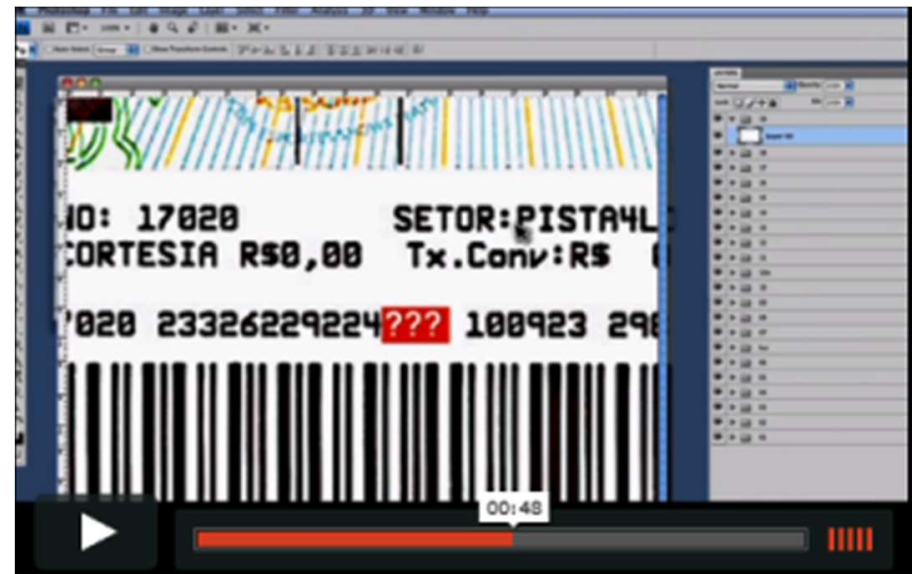

Figura 3: Execução da hipótese abdutiva antefactual - apagamento dos três últimos números

Fonte: Imagem capturada do Vídeo da AlmapBBDO (2015, 48 seg.).

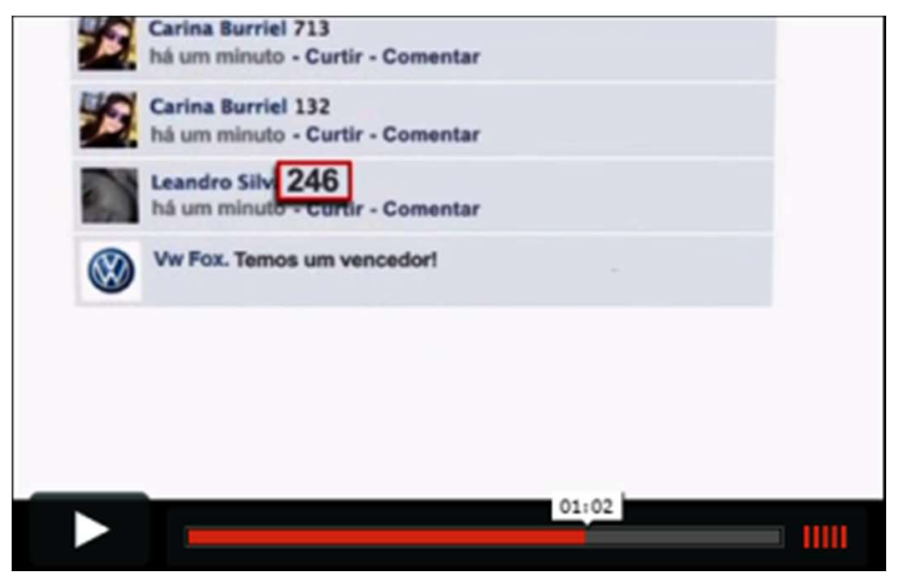

Figura 4: Execução da hipótese abdutiva antefactual - comunicação do sorteio ao usuário

Fonte: Imagem capturada do Vídeo da AlmapBBDO (2015, 62 seg.). 


\subsection{Checagem da hipótese abdutiva antefactual}

Executada a ação, isto é, criada a peça publicitária, ocorre a checagem dedutiva da formulação hipotética "Se P, então Q" no quarto estágio, confluindo com o módulo dedutivo de Sperber e Wilson (1986, 1995).

Vejamos as respectivas formulações:

[4a] Considerando-se [2] "Se $P$, então $Q$ " e [3a] $P$, o indivíduo $i$ checa a consecução $Q$ ' em $t_{4}$, ou

[4b] Considerando-se [2] "Se $P$, então $Q$ " e [3b] $\neg P$, o indivíduo $i$ checa a consecução $\neg Q$ ' em $t_{4}$,

tal que:

a) $t_{4}$ representa o tempo da consecução da meta $Q$;

b) $t_{4}$ sucede $t_{3}$.

c) (4a) é o modelo de consecução da ação $P$ de [3a] e (4b) é o modelo de consecução da inação $\neg P$ de [3b];

d) $Q^{\prime}$ representa o resultado da ação $P$ de [3a] e $\neg Q$ ' representa o resultado da inação $\neg P$ de [3b];

e) $Q^{\prime}$ ou $\neg Q^{\prime}$ é uma realidade em $t_{4}$. (RAUEN, 2014, p. 602-603, tradução nossa).

Nesta formulação, $Q^{\prime}$ representa a provável consecução no tempo $t_{4}$ da meta $Q$ projetada no tempo $t_{1}$. É nesse momento que ocorre a avaliação ou o monitoramento da (in)ação antecedente $P$. No caso em ilustração, uma vez que houve a execução da ação antecedente $P$, versão positiva do modelo; é nesse momento que se avaliam ou monitoram os resultados da ação promocional.

O output do quarto estágio em [4a] pode ser visto a seguir:

[4a] O publicitário $i$ checa a geração de buzz de promoção do carro Fox da Volkswagen antes do Planeta Terra Festival com 30 ingressos em $t_{4}$.

Ou, de forma mais esquemática:

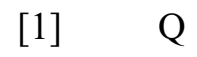

gerar buzz de promoção do carro Fox da Volkswagen antes do Planeta Terra Festival com 30 ingressos, publicitário. 
[2] $\mathrm{P} Q$ criar peça publicitária que concede 30 ingressos do Planeta Terra Festival através da ferramenta "comentário" Facebook, publicitário.

[3] $\mathrm{P}$

[4] criar peça publicitária que concede 30 ingressos do Planeta Terra Festival através da ferramenta "comentário" Facebook, publicitário. gerar buzz de promoção do carro Fox da Volkswagen antes do Planeta Terra Festival com 30 ingressos, publicitário.

Geração de buzz de promoção do carro Fox da Volkswagen antes do Planeta Terra Festival com 30 ingressos, publicitário.

A checagem é o estágio no qual avaliamos a consecução da meta $Q$ no domínio da formulação hipotética “Se P, então Q". Nesse momento, consideramos os conceitos de conciliação de metas e de confirmação de hipóteses. Conforme Rauen (2014, p. 603, tradução nossa), há conciliação de metas quando o estado $Q$ ' do ambiente em $t_{4}$ “satisfaz, coincide com ou corresponde à meta $Q$ em $t_{l}$ ". Ou seja, é o estado no qual o resultado da ação $P$ assemelha-se ou é congruente com o resultado esperado. Além disso, há confirmação de uma hipótese abdutiva antefactual $H_{a}$ quando o estado da realidade $Q$, em $t_{4}$ "satisfaz, coincide com ou corresponde à hipótese $H_{a}$ em $t_{2}$ ". Isto é, o estado no qual “o resultado da ação $P$ reforça a hipótese abdutiva antefactual $H_{a}$ de que a ação antecedente $P$ causa o estado consequente $Q$ ” (RAUEN, 2014, p. 604, tradução nossa).

Com base no conceito de conciliação de metas, Rauen (2014, p. 603, tradução nossa) conjectura haver quatro cenários distintos. No primeiro cenário (5a), há uma conciliação ativa. Neste cenário, “o indivíduo $i$ executa a ação $P$ no contexto da hipótese $H_{a}$, e a realidade $Q^{\prime}$ em $t_{4}$ concilia-se com a meta $Q$ em $t_{l}$ e confirma a hipótese Há em $t_{2}$ ". No caso em ilustração, a agência promove os 30 ingressos ao festival através da ferramenta "comentário" do Facebook e gera um buzz significativo de promoção do carro Fox da Volkswagen com esses 30 ingressos, redundando em sucesso à hipótese abdutiva antefactual.

No segundo cenário (5b), há uma inconciliação ativa. Neste cenário, “o indivíduo $i$ executa a ação $P$ no contexto da hipótese $H_{a}$, e a realidade $\neg Q$ ' em $t_{4}$ não se concilia 
com a meta $Q$ em $t_{1}$ e não confirma a hipótese $H_{a}$ em $t_{2}$ ". Nesse caso, a campanha falha em gerar o buzz, enfraquecendo a força da hipótese abdutiva antefactual de que a campanha no Facebook aumentaria a disseminação do carro Fox da Volkswagen.

No terceiro cenário (5c), há uma conciliação passiva, uma vez que "o indivíduo $i$ não executa a ação $P$ no contexto da hipótese $H_{a}$, e a realidade $Q$ ' em $t_{4}$, mesmo assim, concilia-se com a meta $Q$ em $t_{1}$, embora, tecnicamente, não rejeite a hipótese $H_{a}$ em $t_{2}$ "'. Nesse caso, de viés mais teórico do que prático, apesar da inação da agência, há um buzz aleatório de promoção do carro Fox antes do festival.

No quarto cenário (5d), há uma inconciliação passiva, uma vez que "o indivíduo $i$ não executa a ação $P$ no contexto da hipótese $H_{a}$, e a realidade $\neg Q$ ' em $t_{4}$ não se concilia com a meta $Q$ em $t_{1}$, embora confirme hipótese $H_{a}$ em $t_{2}$ ". No caso em ilustração, a agência não promove a ação no Facebook e, como esperado, não há o buzz de promoção do carro Fox da Volkswagen antes do Planeta Terra Festival com 30 ingressos.

Essas quatro situações podem ser visualizadas a seguir:

Tabela 1: Possibilidades de consecução de metas

\begin{tabular}{|c|c|c|c|c|c|c|c|c|}
\hline \multirow{2}{*}{$\begin{array}{l}\text { Estágios } \\
{[1]}\end{array}$} & \multicolumn{2}{|c|}{$\begin{array}{l}{[5 \mathrm{a}]} \\
\text { conciliação ativa }\end{array}$} & \multicolumn{2}{|c|}{$\begin{array}{l}{[5 \mathrm{~b}]} \\
\text { inconciliação ativa }\end{array}$} & \multicolumn{2}{|c|}{$\begin{array}{l}{[5 \mathrm{c}]} \\
\text { conciliação passiva }\end{array}$} & \multicolumn{2}{|c|}{$\begin{array}{l}{[5 \mathrm{~d}]} \\
\text { inconciliação passiva }\end{array}$} \\
\hline & & Q & & Q & & Q & & $\mathrm{Q}$ \\
\hline$[2]$ & $\mathrm{P}$ & Q & $\mathrm{P}$ & $\mathrm{Q}$ & $P$ & $\mathrm{Q}$ & $\mathrm{P}$ & $\mathrm{Q}$ \\
\hline [3] & $\mathrm{P}$ & & $\mathrm{P}$ & & $\neg \mathrm{P}$ & & $\neg \mathrm{P}$ & \\
\hline [4] & & $Q^{\prime}$ & & $\neg Q^{\prime}$ & & Q' $^{\prime}$ & & $\neg Q^{\prime}$ \\
\hline
\end{tabular}

Fonte: Rauen (2014, p. 606, tradução nossa)

Vale mencionar que a estratégia da AlmapBBDO foi exitosa - conciliação ativa da meta do anunciante. Segundo o case da peça publicitária, o perfil da Volkswagen no Facebook gerou mais de 25.000 comentários, além de obter mais curtidas do que o próprio perfil do evento patrocinado pela marca. Textualmente, a seção de resultados do site se expressa da seguinte maneira: "Em menos de 48 horas foram registrados mais de 25.000 comentários no nosso perfil do Facebook [perfil da Volkswagen], e tivemos mais "Likes" do que o próprio perfil do Planeta Terra Festival" (ALMAPBBDO, 2015, colchetes nossos). A locução do vídeo que acompanha o case, por sua vez, traduz os resultados da seguinte forma: “Alguns ingressos geraram mais de 1.800 comentários. Em menos de 48 horas, nosso perfil [da Volkswagen] teve mais de 25.000 comentários, e recebeu mais 'curtir' do que o próprio perfil do Planeta Terra”. 


\section{Gradação de força de hipóteses abdutivas}

Além das noções de conciliação de metas e de confirmação de hipóteses, Rauen (2014) sugere haver uma gradação na força de conexão entre a ação antecedente $P$ e o estado consequente $Q$ que afeta a avaliação de hipóteses abdutivas antefactuais. Sua tese substantiva é a de que essas hipóteses emergem categóricas por default, ou seja, emergem cognitivamente como verdades absolutas, de forma intuitiva, inconsciente ou automática. Se isso está correto, como explicar situações onde há flexibilização de força (enfraquecimentos ou fortalecimentos) entre a ação antecedente e o estado consequente? A solução é considerar que, embora categóricas por default, as hipóteses podem ser, e de fato geralmente são, auto ou heterocriticadas em seguida. Nesse processo de auto e heterocrítica, hipóteses categóricas podem ser enfraquecidas como bicondicionais, condicionais, habilitadoras ou tautológicas (e mesmo voltarem a ser fortalecidas, através de novas reflexões).

No contexto de hipóteses abdutivas antefactuais categóricas $P \Leftrightarrow Q^{17}$, o indivíduo não cogita qualquer falha a priori. Supostamente, é dessa maneira que a hipótese abdutiva antefactual de consecução da demanda da Volkswagen emergiu cognitivamente, de forma intuitiva, inconsciente ou automática. Em outras palavras, a utilização da ferramenta "comentário" do Facebook para conceder 30 ingressos do Planeta Terra Festival teria emergido cognitivamente como suficiente, necessária e certa para gerar o buzz de promoção do carro Fox.

Todavia, no processo de auto ou heterocrítica que se segue imediatamente, a hipótese abdutiva pode ser enfraquecida em diferentes níveis. Ela pode tornar-se bicondicional $P \leftrightarrow Q$. Nos termos de Rauen (2014, p. 605, tradução nossa), "hipóteses abdutivas se revelam bicondicionais nas inexecuções de $P$, quer em problemas involuntários ou dilemas voluntários". Assim, a conexão entre $P$ e $Q$ não é certa, mas necessária e suficiente, passando o publicitário a considerar inconciliações passivas $[5 \mathrm{~d}]^{18}$.

\footnotetext{
${ }^{17}$ Rauen (2014, p. 605) propõe o símbolo lógico ‘ $\Leftrightarrow$ ' para capturar a conexão suficiente, necessária e certa entre os termos da proposição.

${ }^{18}$ Luciano (2014) modela um exemplo desse tipo de enfraquecimento no qual uma pessoa está a caminho do ponto de ônibus em dúvida se conseguirá ou não pegar o ônibus que a levará a tempo para uma conferência. Neste caso, o tratamento da hipótese abdutiva antefactual de que se a pessoa pegar o ônibus ela irá à conferência como bicondicional se justifica pelo fato de a pessoa estar supostamente atrasada.
} 
Pode haver casos também em que a hipótese abdutiva torna-se condicional $P \rightarrow Q$, de modo que a ação antecedente $P$ se revela suficiente, mas não necessária para o estado consequente $Q$. Nesse contexto, conciliações passivas (5c) passam a ser consideradas. No caso em ilustração, mesmo que teoricamente, cogita-se que, apesar da inação da agência, algo ao acaso poderia gerar o buzz de promoção do carro Fox.

Mais plausível neste contexto, a hipótese abdutiva pode tornar-se habilitadora $P \leftarrow Q^{19}$, de forma que a ação antecedente $P$ se revela necessária, mas não suficiente para atingir o estado consequente $Q$, possibilitando inconciliações ativas (5b). Ou seja, bem poderia ser o caso de se utilizar a ferramenta "comentário" do Facebook para conceder 30 ingressos do Planeta Terra Festival, e isso não garantir a geração do buzz de promoção do carro Fox.

Enfraquecendo ainda mais a conexão entre a ação antecedente $P$ e a consecução da meta $Q$, a hipótese abdutiva pode tornar-se tautológica $P-Q^{20}$, de modo que $P$ não é nem suficiente nem necessário para a consecução $Q$, modelando situações do tipo "Se P, então possivelmente Q". Nesse caso, todos os tipos de consecução são possíveis.

Vale mencionar que também pode ser o caso de o processo de auto e heterocrítica promover o fortalecimento da conexão. Nesses casos, as reflexões produzem argumentos em direção à consecução da ação antecedente, tornando-a necessária, suficiente ou mesmo certa para a consecução da meta.

Considerados esses casos de flexibilização, argumentamos que a criação publicitária é justamente um caso em que uma escolha genuína de hipóteses e uma consideração esclarecida de alternativas de consecução são levadas em conta. Posto isso, os publicitários devem estar preparados para considerar inúmeras variáveis que tendem a enfraquecer (ou mesmo fortalecer) a força de hipóteses abdutivas antefactuais que supostamente atendem à demanda dos anunciantes. Além disso, processos inferenciais humanos são sensíveis ao contexto, de modo que um input pode produzir conclusões diferentes em contextos variados. Isso é desafiador para os publicitários, pois eles precisam constranger essas conclusões para que uma peça publicitária não se desvie das

\footnotetext{
${ }^{19}$ Conforme Rauen (2014, p. 203), “o termo é um empréstimo de Johnson-Laird e Byrne (2002, p. 661). Outra formulação poderia ser $\mathrm{Q} \rightarrow \mathrm{P}$ ".

${ }^{20}$ Rauen (2014, p. 203), a partir de Johnson-Laird e Byrne (2002, p. 660-661), propõe um símbolo lógico que captura a ausência de conexão necessária entre os termos da proposição.
} 
expectativas do anunciante. Nesse contexto, auto e heterocriticar a hipótese de solução antes de torná-la pública é fundamental.

Uma abordagem que lida com esses processos cognitivos de monitoramento é a de Mercier e Sperber (2009) ao propor uma distinção entre dois tipos de inferências: as intuitivas e as reflexivas. Segundo os autores, as inferências intuitivas são ativadas de forma automática e inconsciente através das conexões neuronais. As inferências reflexivas, por sua vez, são processadas lentamente e são conscientemente controladas e restringidas pelas limitações do contexto. Assim, "há uma grande diferença entre intuitivamente aceitar alguma representação como um fato, e aceitar alguma afirmação devido a razões explícitas” (MERCIER; SPERBER, 2009, p. 7, tradução nossa). No caso, enquanto os processos inferenciais intuitivos emergem de um processo cognitivo automático, os processos inferenciais reflexivos derivam da análise consciente de sua plausibilidade ${ }^{21}$.

Logo, inferências reflexivas são fundamentais para a criação publicitária, pois enquanto o módulo de inferências intuitivas não considera razões para aceitação ou descarte de uma nova hipótese, o módulo de inferências reflexivas avalia essa hipótese considerando seus pontos positivos e negativos. Essa ponderação, ressaltamos, pode ser interna quando, por exemplo, avaliamos internamente se expomos ou não nossa opinião sobre um fato - autoconciliação, ou externa quando, por exemplo, expomos nosso ponto de vista, e alguém nos apresenta razões para refutar nossa hipótese - heteroconciliação. Além disso, segundo Mercier e Sperber (2009), esses dois sistemas inferenciais podem concorrer, uma vez que o sistema intuitivo de inferências pode apresentar uma hipótese intuitivamente atraente, e o sistema reflexivo pode inibi-la.

Nesse contexto teórico, Mercier e Sperber (2009) defendem a hipótese de que inferências reflexivas têm a função de avaliar os argumentos utilizados na comunicação. No caso do processo criativo, essa avaliação é essencial, uma vez que não basta ao

\footnotetext{
${ }^{21}$ Essa distinção entre esses dois tipos de inferências vai ao encontro da tese de Evans e Stanovich (2013) de que o raciocínio envolve processos duais do tipo 1 e do tipo 2 . Segundo os autores, os processos do tipo 1 atuam de forma rápida e intuitiva, e os processos do tipo 2 atuam controlando os impulsos do sistema anterior e fornecendo respostas mais deliberadas. Ainda conforme esses autores, o processamento autônomo caracteriza o processamento do tipo 1 e a capacidade de sustentar a dissociação de representações secundárias caracteriza o processamento do tipo 2. Além do mais, "este último é um requisito fundamental para o pensamento cognitivo hipotético" (EVANS; STANOVICH, 2013, p. 237, tradução nossa). Para um aprofundamento sobre esses processos duais, ver Evans (2008), Kahneman (2011), Stanovich (2011), Evans e Stanovich (2013).
} 
publicitário crer que uma proposta formulada será eficiente, é preciso ponderá-la. Em tese, os próprios estágios que envolvem a criação tendem a oportunizar essa reflexão. Definido o problema, colhem-se informações, geram-se ideias, buscam-se e avaliam-se soluções.

Em situações heterocríticas, o grau de confiança que a audiência tem numa hipótese depende do grau de confiança que ela deposita no indivíduo que a submeteu. Conforme Mercier e Sperber (2009), essa confiança que os seres humanos atribuem às fontes pode ser vulnerável e gerar equívocos. Segundo eles, os seres humanos sofrem uma forte pressão para filtrar informações comunicadas com o intuito de chegar o mais perto possível de informações confiáveis. Nesse sentido, argumentam que essa exigência seletiva causa o que eles chamam de vigilância epistêmica. Através da vigilância epistêmica, avalia-se "o comunicador e o conteúdo de suas mensagens, a fim de filtrar a informação comunicada" (MERCIER; SPERBER, 2009).

Essas noções, ressaltamos, além de explicarem como se dá essa avaliação e possível gradação na força da hipótese, são compatíveis com a sugestão de Rauen (2014) de que as hipóteses abdutivas em contextos proativos emergem categóricas, e de que pode haver um enfraquecimento da conexão entre as ações antecedentes e os estados consequentes em situações onde impasses demandam reflexões mais apuradas. Ademais, argumentamos neste artigo que ambas as ilações de Rauen (2014) são plausíveis no contexto da criação publicitária. $\mathrm{O}$ contexto de criação de ideias para atender às metas do anunciante tanto é propício para a emergência a priori e intuitiva de hipóteses abdutivas categóricas, como para a sua imediata avaliação epistêmica reflexiva.

\section{Considerações finais}

Na publicidade, o processo criativo é guiado por uma meta negociada com o anunciante e, em seguida, inserida em um briefing pelo setor de atendimento da agência publicitária. Esse documento é interpretado pelos profissionais de criação, impondo restrições ao processo criativo ao eleger a meta do anunciante, o foco da mensagem, os prazos, os custos, dentre outros elementos que devem ser considerados. Antes da elaboração da campanha publicitária, portanto, há uma etapa abdutiva dirigida por uma meta. 
Assumindo que os insights criativos podem ser definidos como hipóteses abdutivas antefactuais no contexto de uma arquitetura abdutivo-dedutiva guiada pela noção de conciliação de metas (RAUEN, 2014), ilustramos neste artigo o processo de elaboração, execução e checagem dessas hipóteses em uma situação proativa de criação de uma peça publicitária para a Volkswagen, elaborada pela agência AlmapBBDO, cujo objetivo era gerar buzz de promoção do carro Fox antes do Planeta Terra Festival com apenas 30 ingressos. Conforme a teoria de conciliação de metas, a modelação proativa de metas consistiu num processo cognitivo composto por quatro estágios, de tal sorte que, diante da meta de gerar buzz de promoção do carro Fox (a), o publicitário abduziu a melhor hipótese abdutiva antefactual de consecução (b) que foi em seguida executada (c) e checada (d).

Além disso, refletimos sobre a emergência da hipótese e sobre a gradação de sua força. Defendemos que hipóteses abdutivas antefactuais de consecução de metas emergem intuitivamente como categóricas por default (RAUEN, 2014), mas podem ser flexibilizadas em seguida por inferências reflexivas auto ou heteromotivadas (MERCIER; SPERBER, 2009). No mercado publicitário, argumentamos, essa flexibilização é necessária, pois a força de uma hipótese abdutiva de consecução de uma meta é inversamente proporcional à cogitação de seu fracasso. Cogitar o fracasso nestes contextos, portanto, é essencial para o refinamento de qualquer campanha que se propõe a ser bem-sucedida.

RAUEN, Fábio José; LUCIANO, Suelen Francez Machado. Antefactual abductive hypotheses in proactive situations of creating advertising campaigns: analysis with base in goal conciliation theory. Revista do Gel, v. 14, n. 2, p. 225-251, 2017.

\begin{abstract}
We analyze in this article the process of formulation, execution and checking of antefactual abductive hypotheses in proactive situations of creating advertising campaigns from abductive-deductive modeling provided by the goal conciliation theory (RAUEN, 2014). We assume that creativity in advertising is superordinate by goals that the advertising agency service team negotiates with customers, materializes in briefings and delivers to the creative team. In this context, we argue that the emergence and evaluation of the insights can be better understood by conceiving them as abductive hypotheses toward the optimal achievement of goals that are designed in briefings. To illustrate our point, we analyze a video published by AlmapBBDO agency, reporting the case of promotion of the car Fox Volkswagen on Planeta Terra Festival.
\end{abstract}


Keywords: Goal conciliation theory. Proactive modeling of goals. Ante-factual abductive hypotheses. Advertising. Advertising creation.

Submetido em: 10/08/2016.

Aceito em: 18/05/2017.

\section{Referências}

ALMAPBBDO. Case Fox Comments. 2015. Disponível em:

$<$ http://www.551121615600.com/awards/2011/planeta terra face/port/index.html $>$.

Acesso em: 20 out. 2015.

BERTOMEU, J. V. C. Criação na propaganda impressa. São Paulo: Futura, 2002.

BEZ, A. da S. Conciliação de metas, relevância e reestruturação cognitiva de crenças intermediárias. 2016. 176 f. Tese (Doutorado em Ciências da Linguagem) Programa de Pós-graduação em Ciências da Linguagem, Universidade do Sul de Santa Catarina, 2016.

CALDEIRA, F. H. Conciliação de metas em buscas orgânicas no Google: análise das interações usuário-sistema. 2016. 188 f. Tese (Doutorado em Ciências da Linguagem) Programa de Pós-graduação em Ciências da Linguagem, Universidade do Sul de Santa Catarina, 2016.

CARDOSO, M. C. Conciliação de metas, relevância e registros de representação semiótica em matemática. 2015. 173 f. Tese (Doutorado em Ciências da Linguagem) Programa de Pós-graduação em Ciências da Linguagem, Universidade do Sul de Santa Catarina, 2015.

CARRASCOZA, J. A. Do caos à criação publicitária: processo criativo, plágio e ready-made na publicidade. São Paulo: Saraiva, 2008.

CORRÊA, R. Planejamento de propaganda. 8. ed. rev. e ampl. São Paulo: Global, 2002.

DUAILIBI, R.; SIMONSEN JUNIOR, H. Criatividade \& marketing. São Paulo: Makron Books do Brasil, 2000.

EVANS, J. Dual-processing accounts of reasoning, judgment, and social cognition. Annual Review of Psychology. 2008. p. 255-278. Disponível em: $<$ http://www.ncbi.nlm.nih.gov/pubmed/18154502>. Acesso em: 10 jun. 2016.

EVANS, J.; STANOVICH, K. Dual-process theories of higher cognition: Advancing the debate. Perspectives on Psychological Science, v. 8, p. 223-241. Disponível em: $<$ http://scottbarrykaufman.com/wp-content/uploads/2014/04/dual-process-theoryEvans_Stanovich_PoPS13.pdf $>$. Acesso em: 10 jun. 2015. 
HANSEN, F. (In)verdades sobre os profissionais de criação: poder, desejo, imaginação e autoria. Porto Alegre: Entremeios, 2013.

HARMAN, G. The inference to the best explanation. Philosophical Review, v. 74, p. 88-95, 1965.

KAHNEMAN, D. Thinking, fast and slow. New York: Farrar, Straus and Giroux, 2011.

LINDSAY, R.; GORAYSKA, B. Relevance, goal management and cognitive technology. In: GORAYSKA, B.; MEY, J. Cognition and technology: co-existence, convergence, and co-evolution. Amsterdam: J. Benjamins, 2004.

LUCIANO, S. F. M. Relevância e conciliação de metas: adequação lógica e plausibilidade empírica. 2014. 96 f. Dissertação (Mestrado em Ciências da Linguagem) - Programa de Pós-graduação em Ciências da Linguagem, Universidade do Sul de Santa Catarina, 2014.

MERCIER, H.; SPERBER, D. Intuitive and Reflective Inferences. In: Two minds: dual processes and beyond. In: EVANS, J.; FRANKISH, K. (Ed.). Oxford University Press,

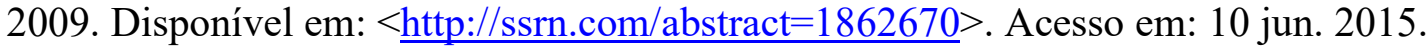

NACHMANOVITCH, S. Ser criativo: o poder da improvisação na vida e na arte. 3. ed. São Paulo: Summus, 1993.

. Why do humans reason? Arguments for an argumentative theory. Behavioral and BrainSciences, v. 34, n. 2, p. 57-74, 2011. Disponível $\mathrm{em}:<\underline{\text { http://papers.ssrn.com/sol3/papers.cfm?abstract } \mathrm{id}=1698090}>$. Acesso em: 10 nov. 2014.

PHILLIPS, P. Briefing: a gestão do projeto de design. São Paulo: Blucher, 2008.

RAUEN, F. J. For a goal conciliation theory: ante-factual abductive hypotheses and proactive modeling. Linguagem em (Dis)curso, Tubarão, v. 14, n. 3, ago./dez. 2014.

SPERBER, D.; WILSON, D. Relevance: communication \& cognition. Cambridge, MA: Harvard University, 1986.

. Relevance: communication \& cognition. 2. ed. Oxford: Blackwell, 1995.

Relevância: comunicação e cognição. Lisboa: Fundação Calouste Gulbenkian, 2001.

STANOVICH, K. Rationality and the reflective mind. New York: Oxford University Press, 2011. 
VIEIRA, S. Conflitos entre usuários e desenvolvedores de soluções informatizadas: estudo de caso com base na teoria de conciliação de metas. 2015. $173 \mathrm{f}$. Tese

(Doutorado em Ciências da Linguagem) - Programa de Pós-graduação em Ciências da Linguagem, Universidade do Sul de Santa Catarina, 2015.

VIEIRA, S. Raciocínio criativo na publicidade: uma proposta. 2. ed. São Paulo: Loyola, 2001.

WEISBERG, R. Modes of expertise in creative thinking: evidence from case studies. In: ERICSSON, K. A. et al. (Ed.). The Cambridge handbook of expertise and expert performance. New York: Cambridge University Press, 2007. p. 761-787. 